\title{
MUJERES EN LA EXPEDICIÓN DE PEDRO DE MENDOZA: CARTAS, CRÓNICAS Y NOVELAS; VERDADES, MENTIRAS, FICCIONES Y SILENCIOS
}

\author{
MAR LANGA PIZARRO \\ marlangap@gmail.com
}

\section{RESUMEN}

Aunque las crónicas apenas se ocupan de las mujeres, diversos documentos certifican la presencia femenina en la expedición de Pedro de Mendoza al Río de la Plata (1535). Probablemente el más hermoso sea la carta de una de las viajeras, Isabel de Guevara, cuya autoría resulta dudosa para historiadores como Groussac. En este artículo, analizamos la misiva, la comparamos con otros textos, y nos acercamos a las obras literarias que han tratado esa aventura, en la que no faltaron un viaje azaroso por el océano, un asesinato, incursiones en territorios remotos, canibalismo, y figuras casi míticas.

Palabras clave: Pedro de Mendoza, crónicas, expediciones, Río de la Plata, Isabel de Guevara, mujeres.

\section{ABSTRACT}

Although little is said in the chronicles of the expedition of Pedro de Mendoza to Río de la Plata (1535) regarding women, many documents certify their presence. Perhaps one of the most beautiful texts is the letter written by Isabel de Guevara which has come under scrutiny by historians like Groussac who doubt its authorship. In this article, the letter is analysed and compared with other texts which bring us closer to the literary works on this adventure which includes an ocean crossing, trips into remote areas, cannibalism, and quasi-mystic figures.

Keywords: Pedro de Mendoza, chronicles, expeditions, Río de la Plata, Isabel de Guevara, women.

Los cronistas premian o castigan, ensalzan o detractan, de muchas maneras, a cual más perversa: cuando no mienten olvidan y solo los hombres inicuos [...] son recordados en las crónicas. Luis Hernáez, 2003, p. 252.

La concepción de la conquista de América como continuidad de la Reconquista supone exaltar valores caballerescos: quienes participaron en ellas, aparecen como reputados gue- rreros, nuevos señores feudales poseedores de tierras y siervos, a los que simultáneamente protegen y explotan. En el imaginario colectivo, los protagonistas siguen siendo varones: a menudo se tiende a ignorar a las mujeres que tomaron las armas; se pasa de puntillas sobre las que ocuparon puestos públicos; se silencian las que influyeron en importantes decisiones; caen en el olvido las que financiaron la Conquista, las que montaron empresas, y los
Mar Langa Pizarro

Doctora en Filología Hispánica. Entre sus publicaciones, destacan Manual de literatura española actual (Castalia, 2007, con Ángel L. Prieto de Paula), La literatura paraguaya actual (UA, 2005, editora), Del franquismo a la posmodernidad (UA, 2000 y 2002) y Guido Rodríguez Alcalá en el contexto de la narrativa histórica paraguaya (UA, 2002, CD-libro). Es autora de capítulos sobre literatura paraguaya en Nueva Historia del Paraguay (Taurus, 2010) e Historia de la Literatura Hispanoamericana III (Cátedra, 2008). Dirige la Página de Autor «Fernando Iwasaki» en la Biblioteca Virtual Miguel de Cervantes. Ha publicado más de un centenar de críticas literarias; ha dictado conferencias en Europa y América; y ultima las correcciones de Españolas de armas tomar. Un acercamiento histórico-literario al primer siglo de Conquista y Colonización rioplatense.
Mujeres en la expedición de Pedro de Mendoza: cartas, crónicas y novelas; verdades, mentiras, ficciones y silencios

MAR LANGA PIZARRO 


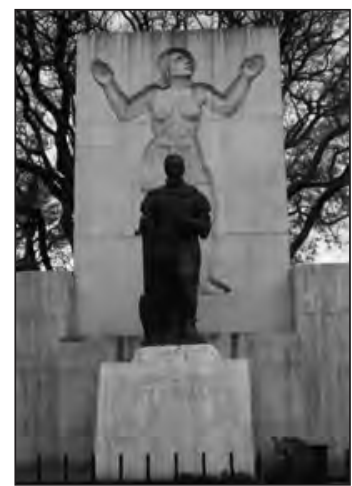

Claudio Elías. Pedro de Mendoza. Parque Lezama. Buenos Aires.

Mujeres en la expedición de Pedro de Mendoza: cartas, crónicas y novelas; verdades, mentiras, ficciones y silencios

MAR LANGA PIZARRO miles de mujeres anónimas que abandonaron su tierra para poblar las Indias.

A pesar de ello, la participación femenina en las expediciones fue tan temprana como creciente: parece que había mujeres ya en el primer viaje colombino (Gil, 1985), está certificada su presencia en el segundo (León, 2000, p. 169), y la Real Cédula de 23 de abril de 1497 autorizaba al Almirante a llevar treinta féminas en su tercera travesía (10\% del total de viajeros). Desconocemos cuántas mujeres pasaron a América porque, como no eran contratadas a sueldo, no figuran en los registros de cuentas. Además, en las listas del pasaje, se incluía a varias personas en el mismo asiento de embarque; por ello, si una mujer no viajaba sola, su nombre solía omitirse, y el asiento aparecía siempre a nombre del varón que la acompañaba. Aun así, entre 1509 y 1607, Condés (2002, p. 129) ha localizado 13.218 pasajeras, lo que supone el $36,25 \%$ del total de inscritos. A ellas habrían de sumarse las viajeras clandestinas, cuyo porcentaje debió de ser mayor que el de varones, ya que requerían licencia de la Corona todas las solteras; las religiosas; las extranjeras; las esposas, hijas y criadas de gitanos; las hijas y nueras de virreyes; las hijas y nietas de procesados por la Inquisición; y los cristianos nuevos de ambos sexos (ibíd., pp. 113-118).

Desde 1515, la Corona insistió reiteradamente en que los conquistadores llevaran a sus cónyuges al Nuevo Mundo. El interés poblador era tan evidente que, en algunos textos, aparecen como una mercadería más. Por ejemplo, en la carta dirigida al Cabildo de Guatemala el 4 de abril de 1539, Pedro de Alvarado informaba de su boda con Beatriz de la Cueva, quien «trae veinte doncellas muy gentiles, hijas de caballeros y de buenos linajes. Bien creo es mercancía que no se me quedará en la tienda nada, pagándomela muy bien» (Fuentes, 1882, p. 108). Han de ser las mismas a las que se refiere el Inca:

llevó [Alvarado] muchas mugeres nobles para casarlas con los conquistadores [...]. Dijo otra: [...] dolos al diablo, parece que escaparon del infierno segun están estropeados; unos cojos y otros mancos, otros sin orejas, otros con un ojo, otros con media cara [...]. Dijo la primera: no hemos de casar con ellos por su gentileza, sino por heredar los indios que tienen, que segun están viejos y cansados se han de morir presto, y entonces podremos escoger el mozo que quisiéremos en lugar del viejo (Garcilaso, 1829 [1609], VII, pp. 484-485).

La anécdota supone un gesto de resignación y picardía ante las imposiciones. Aunque, probablemente, no les dio resultado. Según el mismo Inca, se presionaba a las viudas encomenderas para que volvieran a casarse con quienes los gobernadores querían premiar: «muchas viudas pasaron por ello; á otras muchas se les hizo mal porque les cupieron maridos mas viejos que los que perdieron» (ibid., VI, p. 11).

Las españolas que abandonaron su tierra en busca de un mejor futuro se encontraron en América con una sociedad diferente, pero con las mismas exigencias que en Europa: ejercer de esposas, procrear. Como en todas partes, solo algunas lograron sortear ese destino de sometimiento y silencio.

\section{Españolas en las primeras expediciones al Río de la Plata}

Varias obras han rescatado últimamente la azarosa expedición de doña Mencia Calderón, que partió de España en 1550, y llegó a Asunción en 1556, con medio centenar de mujeres a bordo. Sin embargo, no fueron ellas las primeras españolas en esa zona, que se conocía oficialmente desde hacía cuatro décadas.

Según la versión más difundida, el primer viaje al Río de la Plata salió de Sanlúcar el 8 de octubre de 1515, casi en secreto, para evitar que Portugal saboteara la búsqueda española de un nuevo paso hacia las Indias Orientales. La arribada de Solís a lo que llamó el Mar Dulce se habría producido en alguna fecha indeterminada de 1516. No obstante, se sabe que hubo incursiones portuguesas anteriores, y resulta altamente probable que el mismo Solís hubiera estado allí previamente. Las noticias sobre la expedición son tan incompletas y contradictorias que no puede descartarse taxativamente la presencia femenina solo porque no se conserven informes sobre ella. De vuelta a España, algunos acompañantes de Solís naufragaron en Santa Catalina (actual Brasil), donde los encontraron años después con sus mujeres e hijos: o viajaban españolas con Solís o había comenzado el mestizaje.

En 1526, las expediciones de Sebastián Caboto y Diego García llegaron al «Mar Dulce» o «Río de Solís». Un año más tarde, 
se fundó el fuerte de Sancti Spiritu, devastado por los indígenas en 1529. Según los cronistas, la causa de la destrucción fue la pasión desenfrenada de un cacique por una de las españolas que viajaban con Caboto: Lucía Miranda, la primera cautiva conocida del Río de la Plata. Desde que Eduardo Madero cuestionara estos hechos en 1892, mucho se ha discutido la presencia femenina en la expedición de Caboto. Para negarla, José Toribio Medina acudió a las instrucciones de Carlos I, quien ordenó «que bajo ningún pretexto permitiese que se embarcase mujer alguna 'por evitar los daños é inconvenientes que se siguen é cada día acaecen de ir mujeres en semejantes armadas» (Medina, 1908, p. 90). Ignoramos si Caboto obedeció el mandato, que aparecía junto a estos otros:

le encargaba especialmente que por ningún concepto tocase en isla ni tierra de la Corona de Portugal; $[\ldots .$.$] le prohibía que [. .$.$] virase durante el viaje, sin$ llamar á consejo á todos [...]; que todos los que iban en la armada habían de tener completa libertad para escribir acá todo lo que quisiesen, «sin que por vos ni por otra persona alguna les sea tomada carta ni defendido que no escriba»; [...] «Otrosí, vos encargamos y mandamos que con toda industria é diligencia procuréis $[. .$.$] como más importante y provechoso,$ sea de llegar á las nuestras Islas de los Malucos, é si hallardes [...] el Comendador Loaísaes [...] les socorráis $[\ldots] »(i b i d$. $)$.

Pues bien: según Medina (ibíd., p. 103), Caboto recogió las cartas de la tripulación antes de salir de Canarias; desembarcó en Pernambuco, que era territorio portugués; al saber allí de la existencia de oro y plata, convocó a su gente para acordar el cambio de ruta; cuando Rojas se opuso, le inició un proceso y planeó matarle; y, como ya sabemos, se adentró en el continente, abandonando la búsqueda de las Malucas y la ayuda a Loaysa. Visto todo esto, nos preguntamos si la existencia de una instrucción real es suficiente para asumir que Caboto obedeciera, y no llevara mujeres. Enrique de Gandía (1943) parece aceptarlo pero, como la historia de Lucía Miranda forma parte de los recuerdos de otros expedicionarios, supone que Díaz de Guzmán (1612) debió de confundir las fechas: Lucía habría viajado en la armada de Mendoza, y su cautiverio entre los indígenas habría comenzado con la destrucción del fuerte de Corpus Chisti.
Las diferentes tesis han dejado a Lucía en un limbo aprovechado por la fabulación literaria. Su historia ha inspirado a creadores de todas las latitudes, que han escrito tragedias (Thomas Moore, Mangora, King of the Timbusians, 1717; Manuel José de Lavardén, Siripo, 1789), dramas (Pedro Pablo Bermúdez, El charrúa, 1853; Miguel Ortega, Lucía Miranda, 1864), novelas (las homónimas Lucía Miranda, de Eduarda Mansilla, 1856; Rosa Guerra, 1860; y Hugo Wast, 1928), poemas (Celestina Funes, Lucía Miranda, episodio nacional, 1883) e incluso una ópera (Felipe Boero y Luis Bayón Herrera, Siripo, 1924).

\section{Mujeres en la expedición de Pedro de Men- doza}

Colonizar la zona interesó particularmente a la monarquía española desde 1530, cuando el embajador Lope de Hurtado denunció las pretensiones del rey portugués sobre esas tierras. La gestiones que condujeron al nombramiento de Pedro de Mendoza como primer adelantado del Río de la Plata se iniciaron en 1533, gracias a la intervención de su pariente, la mecenas María de Mendoza, una mujer que influyó en múltiples decisiones de la Corte: quería casar a su hermana con Hernán Cortés, por lo que favoreció que lo nombraran marqués del Valle de Oaxaca, pero como él optó por Juana de Zúñiga, impidió que llegara a ser virrey, y postuló para el cargo a su pariente Antonio de Mendoza (1535). Además, propició que el gobernador Pedro de Alvarado rompiera la promesa de casarse con la prima de Cortés, para hacerlo con Beatriz de la Cueva, quien suplió hábilmente a su marido durante sus ausencias, hasta que la muerte de este propició que el Cabildo de Guatemala la nombrara gobernadora (1541), contradiciendo al virrey.

Las Capitulaciones con Pedro de Mendoza se firmaron el 21 de mayo de 1534. En julio del año siguiente, Isabel de Castilla instó al adelantado: «que os deys tanta priesa que os sea posible» (Schultz, 2006, p. 9). La mayor armada enviada hacia América hasta aquel momento salió de Sanlúcar el 24 de agosto de 1535. Estaba integrada por gentes de todas las categorías sociales, incluidos más de treinta mayorazgos; el hermano de leche de Carlos I, Carlos Dubrín; y el hermano favorito de Santa Teresa de la Cruz, Rodrigo de Cepeda, el mismo con el que durante la
Mujeres en la expedición de Pedro de Mendoza: cartas, crónicas y novelas; verdades, mentiras, ficciones y silencios

MAR LANGA PIZARRO 


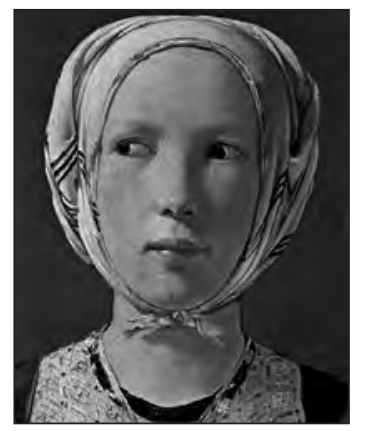

George de La Tour, La lectora de la buena fortuna. The Metropolitan Museum. Detalle.

1

Para agilizar la lectura, en el caso de los cronistas que más vamos a citar (Schmidl, Luis Miranda y Díaz de Guzmán), solo se ofrecerá el número de verso o de página. Tampoco daremos referencias de la carta de Francisco de Villalta (22 de junio de 1556; conservada en la Biblioteca de la Real Academia de la Historia, Colección de Muñoz, tomo 80 folios 331-341, 1536-56) ni de la de Isabel de Guevara (2 de julio de 1556; "Carta de doña Isabel de Guevara», en Cartas de Indias, Madrid, Ministerio de Fomento, 1877, pp. 619-621). Remitimos a la bibliografía final para más información.

Mujeres en la expedición de Pedro de Mendoza: cartas, crónicas y novelas; verdades, mentiras, ficciones y silencios

MAR LANGA PIZARRO infancia, hinchada la imaginación por leer vidas de santos, la santa había concertado ir «a tierra de moros [...] para que allá nos descabezasen» (1861 [1560], p. 24). También viajaban el bávaro Ulrico Schmidl, autor de Viaje al Río de la Plata (1567); y el clérigosoldado Luis de Miranda, que escribió en Asunción una crónica en versos de pie quebrado, compuesta en torno a 1545 aunque inédita hasta el siglo XVIII ${ }^{1}$.

La presencia femenina en la expedición no está avalada por las Capitulaciones, que sí fijaban el número de equinos («cien caballos y yeguas»), y la obligación de llevar «mil hombres, los quinientos en el primer viaje [...] y dentro de dos años siguientes los otros quinientos» (Medina, 1889, pp. 278283). Schmidl reduce el número de animales («72 caballos y yeguas», p. 147) y aumenta el de los varones: «2500 españoles y 150 altoalemanes, neerlandeses y sajones» (p. 156), pero no menciona a las mujeres. Tampoco las nombra Díaz de Guzmán: «traía 2200 hombres entre oficiales y soldados» (p. 30). La misma omisión comete en su carta de 1556 el expedicionario Francisco de Villalta: solo cita «1800 hombres que traia en armada». La disparidad numérica no resulta fácil de explicar, ni siquiera considerando que todo el pasaje de una de las naves pereció al hundirse frente a la costa brasileña; y que Alonso de Cabrera, con doscientas personas a bordo de la Santiago, cambió de rumbo y regresó a España, antes de volver a dirigirse al Río de la Plata, donde encallaría en 1538. Tampoco resulta lógico el silencio sobre las mujeres, ya que diversos documentos certifican la presencia femenina en la armada de Mendoza.

Hay seis mujeres en el muy incompleto registro de pasajeros. Elvira Hernández figura sola en el asiento 1969; y en el asiento de su marido (el 1627) aparece Catalina de Vadillo. Están inscritas también dos Mari Sánchez. Una integra la familia Arrieta (asiento 1341), junto a su marido y la hija de este, Ana de Arrieta, pero «falta averiguar [...] si [...] embarcaron en las naos de don Pedro de Mendoza, como dice el título del documento, o en la de Hernando Blas, rumbo a Santo Domingo, como se especifica en los asientos» (López, 1975, p. 100). La otra Mari Sánchez viajó acompañada de su cónyuge, Juan Salmerón, aunque él comparta el asiento 1407 con su hermano, y ella se registre sola tres días después (asiento 1459).
De María Dávila, criada del adelantado y contagiada de sífilis, sabemos gracias a uno de los tres codicilos dictados por Pedro de Mendoza entre el 11 y el 13 de julio de 1537, poco antes de morir: "Ytem encargo a mis albaçeas e testamentarios que a maria davila que va doliente en esta nao, le den en llegando a sevilla lo que les paresçiere para que se pueda curar» (Anales de la Biblioteca, 1912, p. 166).

La participación de María Díaz se deduce porque dictó testamento en Asunción en 1537 (Monte, 2006, p. 541). Isabel de Arias consta gracias al poder que le otorga su marido en Asunción, en 1545 (Lafuente, 1943, p. 64). Juana Martín de Peralta únicamente aparece en el testamento de su esposo, fechado el 24 de noviembre de 1547, donde detalla la hija y los cuatro hijos que la pareja tuvo en Asunción (ibid., p. 105). María Duarte figura en varios documentos como esposa de alguno de los Francisco Ramírez embarcados con Mendoza (ibid., p. 555). De Martina Espinoza queda su testamento, de 1547: dejó bienes a su esposo, Hernand Sánchez, que Monte (2006, p. 542) identifica con un carpintero granadino que viajó con Mendoza. Sobre Ana Fernández, beneficiaria en un documento firmado por Cabeza de Vaca (1544), Monte (ibid., p. 543) plantea que podría ser familia de alguno de los diez expedicionarios mendocinos apellidados Fernández. Por su implicación en varios litigios conocemos a Isabel de Quiroz, quien declaró el 8 de enero de 1543 en un pleito emprendido por Sebastián Valdivieso contra la ya difunta Luisa de Torres. También un juicio permite saber de otras dos expedicionarias: en 1543, Isabel Martínez testificó en Asunción para ratificar la declaración de su amiga Ana de Rivera contra Luis Ramírez (ibid., p. 548).

$\mathrm{Ni}$ siquiera la preciosa carta de Isabel de Guevara (1556) despeja dudas sobre el número total de féminas: «avemos venido çiertas mugeres $[\ldots]$ con mill é quinientos hombres».

La travesía resultó muy dura, ya que pronto escaseó el agua. El expedicionario Alonso de Ochoa relata: "cayeron víctimas de la sed nueve hombres, una mujer y nueve caballos» (Fitte, 1980, p. 104). Según los testimonios recogidos por José Torre Revello, el pasaje hubo de aprovechar el agua de lluvia: «cogian con paños con lo que corria por la jarçia» (1941, p. 220), «vevian agua llovediza que cojian en savanas y en man- 
teles y en escudillas» (ibíd, p. 221). Ante la insuficiencia de esos medios, paliaron la sed con vino sin diluir, lo que provocó varias muertes: «enfermedad hay por beber vino puro estando malos y que después que falto el agua fallecieron syete u ocho personas» (ibid, p. 220). Pero incluso el vino se acabó: «se vevio todo el vino que yva enla nao queno quedaron syno dos pipas y media o tres» (ibíd, p. 220). Así, al llegar a Santo Domingo, hacía tiempo que escaseaban los líquidos: «anduvieron mas de dos meses syn agua e por que ya quando llegaron a Santo domingo no les quedava ya casy vino que beber» (ibíd, p. 221). La terrible situación solo mejoró en Brasil: «syno fuera por que tomaron tres pipas de agua enla Costa del vrasyl de las quales yçieron seys o syete de vino aguado que mucha gente falleçiera» (ibid, p. 220).

Para colmo, hubo graves conflictos entre la tripulación. La sífilis del adelantado lo obligó a delegar en Juan de Osorio, a quien acabó mandando matar el 3 de diciembre de 1535. Antes de iniciar su inconcluso regreso a España, el 10 de abril de 1537, Pedro de Mendoza hizo sacar un traslado del proceso contra Osorio, donde consta la feroz sentencia: «sea muerto a puñaladas o estocadas, o en otra cualquier manera que lo pudiera ser, las quales le sean dadas hasta que el alma le salga de las carnes; al qual declaro por traydor y amotinador, y le condeno en todos sus bienes» (Groussac, 1916, p. 16). Díaz de Guzmán narra así los hechos:

Juan de Osorio, [...] al cual todos querían y estimaban por su grande afabilidad y valor [...] estando en dicho puerto [Río de Janeiro], sucedió un día que andando el maestre de campo Juan de Osorio paseándose [...], llegó a él Juan de Oyolas, alguacil mayor, y le dijo, (yendo en su compañía el capitán Salazar, y Diego de Salazar y Medrano): «Usted sea preso, señor Juan de Osorio»; [...] todos se fueron hacia la tienda del gobernador [...]: «hagan lo que han de hacer»; y volviendo a donde venía el maestre de campo, de improviso le dieron de puñaladas, que cayó muerto, sin poder confesar: luego pusieron el cuerpo sobre un repostero a vista de todo el campo con un rótulo: -por traidor y alevoso- [...]. Súpose que algunos envidiosos le malsinaron con don Pedro, diciendo, que el maestre de campo le amenazaba, [...] de cuya muerte sobrevinieron, por castigo de Dios, grandes guerras, muchas desgracias y muertes (1835 [1612], pp. 30-32).
Algunas personas que presenciaron el asesinato testificaron en el largo juicio que inició, en agosto de 1537, el padre de Juan de Osorio, Juan Vázquez de Orejón, contra Juan de Ayolas, Juan de Salazar y los herederos del adelantado. El 5 de marzo de 1544, el Consejo de Indias revocó la sentencia de muerte de Osorio, le restituyó su honra, ordenó la devolución de sus bienes, y condenó a los descendientes de Mendoza a pagar mil ducados y las costas del proceso. Entre los testigos de 1541 figuran dos mujeres: Catalina Pérez (criada del adelantado) y Elvira Pineda (criada de Osorio). Ambas viajaron al Río de Plata con la armada de Mendoza y se supone que volvieron con él, en 1537.

No acabaron los problemas una vez alcanzaron el Río de la Plata. Acosados por los ataques de los nativos y, sobre todo, por una terrible hambruna, Schmidl explica: "ya no quedaban ni ratas, ni ratones, ni culebras, ni sabandija alguna que nos remediase en nuestra gran necesidad e inaudita miseria; llegamos hasta comernos los zapatos y cueros todos» (p. 152). Villalta corrobora la penuria: «hera tanta la necesidad i hambre que pasaban que hera espanto, pues unos tenian á su Compañero muerto 3 i 4 días i tomaban la racion por poderse pasar la vida con ella». Los expedicionarios coinciden en que el hambre los obligó a practicar la coprofagia y la antropofagia. Dice Miranda: «el estiércol y las heces, / que algunos no digerían, / muchos tristes los comían / que era espanto; / allegó la cosa a tanto, / que, como en Jerusalén, / la carne de hombre también / la comieron» (vv. 77-84); añade Villalta: «de berse tan Ambrientos les aconteció comer carne humana, $i$ así se bido que asta 2 ombres que hicieron justicia se comieron de la cintura para abaxo»; y explica Schmidl:

tres españoles se robaron un rocín y se lo comieron sin ser sentidos; mas cuando se llegó a saber los mandaron prender e hicieron declarar con tormento; y luego que confesaron el delito los condenaron a muerte en horca [...]. Esa misma noche otros españoles se arrimaron a los tres colgados en las horcas y les cortaron los muslos y otros pedazos de carne [...] para satisfacer el hambre (p. 152).

Estas circunstancias son recogidas también por Díaz de Guzmán: «los excrementos de los unos, comían los otros; [...] los vivos se sustentaban de la carne de los que morían, y aun de los ahorcados por justicia» (p. 36).
Mujeres en la expedición de Pedro de Mendoza: cartas, crónicas y novelas; verdades, mentiras, ficciones y silencios

MAR LANGA PIZARRO 
Carlos I, enterado de los hechos, dictó una Real Cédula fechada en Valladolid el 20 de noviembre de 1539 , por la que los perdonaba y les enviaba, además de armas, a seis franciscanos. Así lo narra el Cronista Mayor de Indias, Antonio de Herrera:

Embio a si mismo el Rey vn galeon con Antó Lopez de Aguiar cargado de armas, y municiones [...], y seys religiosos de la orden de san Francisco para celebrar, y porq se entendió q la extrema hambre que aquellos Castellanos auian padecido, los auia forçado à comer carne humana, [...] el Rey los perdonô, i mandô, q los recibiessen sin castigarlos (1615, p. 101).

Canibalismo certificado por tanto, aunque algunos hechos concretos los narre Díaz de Guzmán con cautela: «y tal vez hubo que un hermano sacó las asaduras y entrañas a otro que estaba muerto para sustentarse con ellas» (p. 36). Sin embargo, también los cronistas presenciales lo dan por cierto: «un español se comió al hermano que había muerto en la ciudad de Bonas Ayers» (Schmidl, p. 152); «las cosas que allí se vieron / no se han visto en escritura: / ¡comer la propia asadura / de su hermano!» (Miranda, vv. 85-90). Con más detalle lo relata Centenera: «estaban dos hermanos; / de hambre el uno muere, y el rabioso / que vivo está, le saca los livianos / y bofes y asadura, y muy gozoso / los cuece en una olla por sus manos / y cómelos; y cuerpo se comiera» (1854 [1602], vv. 1274-1279).

Semejante hambruna diezmó la expedición mendocina: Schmidl apunta «de 2500 hombres que habían sido, no quedaban con vida más de 560» (p. 156), cifra final que concuerda con la de Isabel de Guevara: «era tamaña el hambre, que, a cabo de tres meses, murieran los mill» (de mil quinientos). Va todavía más lejos Miranda: «de dos mil aun no quedamos / en doscientos» (vv. 59-60). ¿Murieron dos tercios, como dice Guevara; casi tres quintos, como escribe Schmidl; nueve de cada diez, como sostiene Miranda? Imposible determinarlo. En cualquier caso, el panorama resulta devastador. Por eso, la labor de las mujeres, narrada por Isabel de Guevara y silenciada por sus compañeros, adquiere todavía más importancia:

Mujeres en la expedición de Pedro de Mendoza: cartas, crónicas y novelas; verdades, mentiras, ficciones y silencios

MAR LANGA PIZARRO fuegos, armar las vallestas, [...] cometer á poner fuego en los versos, y á levantar los soldados, [...] dar arma por el campo á bozes, sargenteando y poniendo en orden los soldados; porque, en este tiempo, como las mugeres nos sustentamos con poca comida, no aviamos caydo en tanta flaqueza como los hombres.

Según Isabel, se encargaron de sus funciones habituales, y de las que normalmente hacían los varones: «sino fuera por ellas, todos fueran acabados», concluye. Para lograrlo, debía de haber más mujeres de las que nos constan: Piossek (2003) da once nombres; Da Luz (2001) afirma que fueron una veintena; Monte (2006) estudia a veintidós; y en la lista de diez que ofrece Rossi (1997, p. 24), hay una que las demás no contemplan. Si Guevara no miente, probablemente fueron muchas más, pero quizá nunca lleguemos a saberlo.

Aunque se puede argumentar que una carta destinada a pedir el favor real, como la escrita por Isabel de Guevara, suele exagerar los datos, ya hemos visto que, cuando da cifras, Guevara es, con diferencia, la más comedida de quienes presenciaron los hechos. Además, la autora avala su verdad planteando que pueden corroborarla los propios expedicionarios: «los diera á hellos por testigos». Habían pasado veinte años desde la llegada a Buenos Aires hasta la escritura de la misiva: cualquiera podía aún verificar los testimonios. Recuperemos un fragmento algo más largo de esa frase: «si no fuera por la honrra de los hombres, muchas mas cosas escriviera con verdad y los diera á hellos por testigos. Esta relaçion bien creo que la escrivirán á $\mathrm{V}$. A. mas largamente, y por eso sesaré». Probablemente, lo que calla es el canibalismo. Puesto que, para entonces, hacía años que habían recibido el perdón real, interpretamos como un gesto de elegancia la omisión de unos hechos desagradables y cuestionables, de los que ya suponía sabedora a su destinataria.

$\mathrm{Al}$ igual que sus compañeros de viaje, las crónicas posteriores omitieron la presencia de Isabel de Guevara, y apenas se ocuparon de las otras féminas. Díaz de Guzmán únicamente narra la historia de «La Maldonada» (p. 39), quien, desesperada por el hambre, sale del recinto fortificado, y se refugia en una cueva, donde ayuda a parir a una leona. Posteriormente se convierte en cautiva de los indígenas. Cuando los españoles la encuentran, Francisco Ruiz o el capitán Alvarado, 
según las versiones, ordena que la aten a un árbol desnuda, para que sea devorada por las fieras y eso sirva de escarmiento. Sin embargo, cuando acuden a buscar sus restos la hallan viva, porque la leona la ha protegido.

En la historia confluyen elementos de resonancias legendarias (la ayuda mutua de la protagonista y la leona), otros verosímiles (la huida de la hambruna), y un castigo que solo se explica por los usos de la época: en su edición de la obra, Gandía sostiene que «el relato de La Maldona puede ser verídico, pues Francisco Ruiz Galán tenía la costumbre de castigar a los conquistadores atándolos a un árbol para que los comieran las fieras. Antonio de la Trinidad, por ejemplo, lo acusó de este delito» (1986, p. 128). Además, entenderemos mejor la sanción si consideramos que estamos ante una cautiva:

Si el cuerpo una mujer preparado para ser un dominio del hombre civilizado es erosionado por el cuerpo bárbaro de su captor, entonces la impureza, el envilecimiento, la convertirán en abyección [...]. El acto sexual deja de ser ley natural [...] para convertirse en lo siniestro [...]. El rescate no ofrece ni siquiera reparación simbólica para la mujer [...] no redime ni salva a la cautiva $[. .$.$] del pecado finalmente$ original de tener un cuerpo de mujer. La redención sólo adviene con el martirio y la muerte (Iglesia, 2006, 585-586).

Tampoco Centenera dedica mucha atención a las mujeres de la armada mendocina. Solo se detiene en una tal Ana:

Una mujer había, llamada Ana, / entre otras damas bellas y hermosas; / tomó paga del cuerpo una mañana, / forzada de la hambre, y echa iguala [...]. / Era el galán pretenso un marinero, / el precio una cabeza de pescado; / acude a la posada muy ligero, / y viendo que la dama le ha burlado, / al capitán Ruiz, buen justiciero, / de la dama se había querellado, / el cual juzga que cumpla el prometido, / o vuelva lo que tiene recibido (1854 [1602], vv. 1308-1320).

¿Quién era Ana? De las varias hipótesis, la más generalizada apunta a Ana de Arrieta, que habría viajado con su padre Diego. Centenera no lo aclara, pero sí establece que sexo a cambio de una cabeza de pescado es un precio que le parece justo al capitán Ruiz, el mismo que mencionaba de Gandía para avalar la historia de La Maldonada.

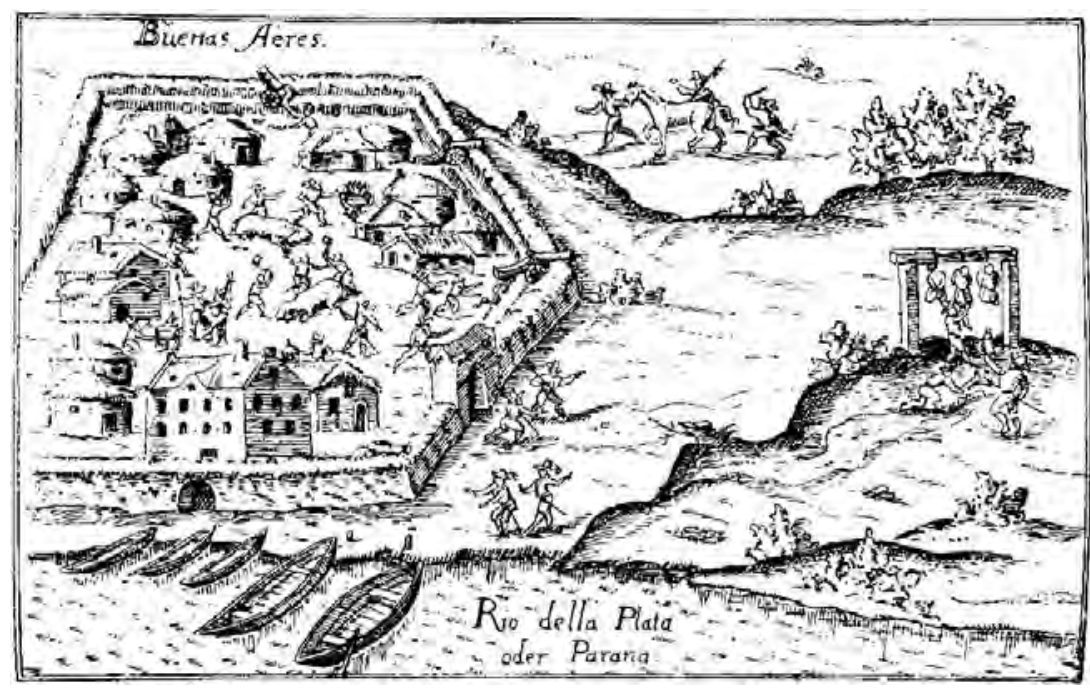

Levino Hulsio. Grabado para el libro de Schmidl, Viaje al Río de la Plata, 1567.

Tanto Centenera como Díaz de Guzmán aluden indirectamente a otra mujer de la armada mendocina. Aunque ni María de Angulo ni su padre, Juan Manrique, figuran en registro de pasajeros, sabemos por los cronistas que él murió a manos de los indígenas, en 1536. María de Angulo debió de establecerse pronto en Asunción, pues su primer hijo nació allí a finales de 1538 (Lafuente, 1937, pp. 414-415). Después, tuvo dos hijas y otro hijo con el capitán Francisco de Mendoza, que fue decapitado por orden de Diego de Abreu. Poco antes de la ejecución, la pareja contrajo matrimonio. Díaz de Guzmán cambia el nombre de la dama al relatarlo: «una noble señora llamada Doña Francisca de Angulo, con quien casó en el artículo de la muerte» (p. 77). Centenera alude al asesinato de esta mujer durante la emboscada que los chiriguanos le tienden a Salazar (1573), y no evita emitir un juicio sobre ella, probablemente influido por unas preferencias políticas que no coincidían con las del esposo de la fallecida: «doña María de Angulo, causadora / de motines, revueltas y pasiones, / amiga de mandar, y tan señora / que con todos tramaba disensiones» (vv. 9111-9114).

Sigamos con la expedición mendocina. El hambre volvió a golpearla cuando emprendió un duro viaje río arriba: según Villalta, «murieron casi 100 hombres de pura hambre». De nuevo Guevara evita las cifras, y se centra en la labor de las mujeres:

las fatigadas mugeres los curavan [...] les guisauan la comida, trayendo la leña á cuestas de fuera del navio,
Mujeres en la expedición de Pedro de Mendoza: cartas, crónicas y novelas; verdades, mentiras, ficciones y silencios

MAR LANGA PIZARRO 


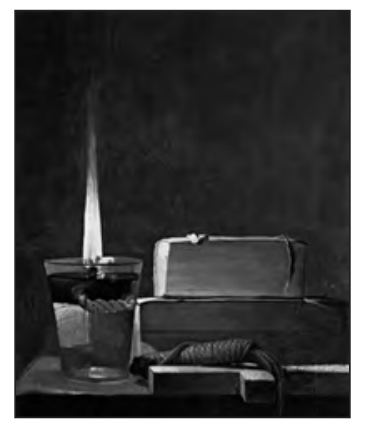

Georges de La Tour, Magdalena de la lamparilla. Detalle.
Mujeres en la expedición de Pedro de Mendoza: cartas, crónicas y novelas; verdades, mentiras, ficciones y silencios

MAR LANGA PIZARRO y animandolos [...] metiendolos á cuestas en los vergantines $[. .$.$] todos los serviçios del navio los toma-$ van hellas [... serviendo de marear la vela y gouernar el navio y sondar de proa y tomar el remo al soldado que no podia bogar y esgotar el navio, y poniendo por delante a los soldados que no desanimasen.

Cuando se habla de la fundación de Asunción, Villalta da todo el mérito a la labor militar de los españoles («con estos trabajos andubimos quitando la comida i quitándola por fuerza é peleando con los naturales de la Tierra»); según Schmidl, son los indígenas los que construyen el fuerte («se vieron obligados los carios a levantarnos una gran casa de piedra, tierra y madera, para que si con el andar del tiempo llegase a acontecer que se levantasen contra los cristianos, [...] pudiesen defenderse», p. 156); en el relato de Isabel de Guevara, las artífices son de nuevo las mujeres, que han de suplir la falta de salud y ánimo de los varones: "fué nesesario que las mugeres boluiesen de nuevo á sus trabajos, haziendo rosas con sus propias manos, rosando y carpiendo y senbrando y recogendo el bastimento sin ayuda de nadie, hasta tanto que los soldados guareçieron de sus flaquezas».

Quienes escriben cartas se quejan del reparto de bienes: Villalta sostiene que no se premió a los conquistadores, sino a quienes llegaron más tarde («la Repartió entre muchas personas que no se hallaron á la ganar, quitándola aquellos que la conquistaron i derramaron su sangre por ganalla»). Según Guevara, se beneficiaron solo los hombres, «ansi de los antiguos como de los modernos, sin que de mi y de mis trabajos se tuviese nenguna memoria, y me dexaron de fuera, sin me dar yndio ni nengun genero de serviçio». Tras las quejas, llegan las peticiones: Villalta solicita una alcaldía de minas para un conquistador ( V. S. me hiciese merced de la Alcaldía de minas para Antonio Martin es caso ques uno de los Conquistadores biejos i á pasado en esta Tierra muchos trabajos»), Guevara pide tierras para sí misma y un cargo para su marido: «estoy casada con [...] Pedro d'Esquiuel, [...] suplico mande me sea dado mi repartimiento perpétuo, y en gratificaçion de mis serviçios mande que sea proveydo mi marido de algun cargo, [...] pues él, de su parte, por sus serviçios lo merese».

Monte (2006, p. 550) da por seguro que la misiva de Isabel de Guevara llegó a España gracias al esposo de Mari Sánchez, Juan
Salmerón de Heredia, que regresó en 1557, llevando las probanzas de méritos de los conquistadores que no habían logrado encomiendas. El documento fue erróneamente clasificado como «carta de doña Isabel de Guevara [...] pidiendo repartimiento para su marido». Quizá quien lo leyó no diera crédito a que una mujer pidiera tierras para ella.

Tampoco lo creyó el historiador Paul Groussac, quien no dudó en calificar la misiva como un «revoltillo de lugares comunes y exageraciones, redactada, al parecer, por algún tinterillo de la Asunción» (1916, p. 73). Groussac duda de su autoría porque, según él, la escritura era un «hecho desusado» en las mujeres de ese tiempo. Debía de ignorar el libro de caballerías de Beatriz Bernal, Don Cristalián de España (1545); y las obras de religiosas de la misma época, como Teresa de Jesús, Ana de Jesús y María de San José. Seguramente desconocía la sabiduría de la escritora humanista preceptora de la reina Isabel, Beatriz Galindo (La Latina); y de sus contemporáneas: la matemática Elvira de Alba; la poeta y filósofa Luisa de Medrano, docente en la Universidad de Salamanca; Francisca de Nebrija, que colaboró con su padre en la redacción de la primera Gramática castellana (1492), y lo sustituyó en la Cátedra de Gramática de Alcalá; Isabel de Vergara, traductora de Erasmo; Luisa Sigea, que escribió obras en varias lenguas y, en 1546, dirigió una carta al papa Pablo III, en latín, griego, árabe, caldeo y hebreo. Tampoco parecía saber el historiador que el fenómeno no era exclusivo de España: María de Portugal, bisnieta de Isabel la Católica, se rodeó de una corte de sabias y eruditas; la poeta Vittoria Colonna tuvo gran influencia en el Renacimiento italiano; Gaspara Stampa fue llamada la nueva Safo; Lucrezia Marenelli publicó Della Nobiltà et eccellenza delle donne (1591); Veronica Gambaro, «cara ad Apollo e alle muse», combinó la política con la literatura... No seguimos con la lista, que podría resultar interminable.

Además, aunque impregnado de belleza literaria, el texto de Isabel de Guevara solo pretendía ser una carta. Amy Schiess evidenció que «la forma epistolar ha sido particularmente accesible a las mujeres, en contraste con las otras formas del discurso escrito» (2006, p. 12); y María Graciela Berg constató: «durante los primeros siglos de Colonia, las mujeres de Buenos Aires le escribieron al rey por diversos motivos. Era no solamente lícito 
sino muy aceptable el acto epistolar para dar noticias, quejas y comentarios al Rey y al Consejo de Indias» (2006, p. 98). Es decir, exactamente lo mismo que hace Isabel de Guevara. Pero no es eso todo: imaginemos por un instante que nuestra autora fuera analfabeta, como lo quiere Groussac. Analfabeta era también Catalina de Siena (siglo XIV), y ello no impidió que dictara cartas dirigidas a sabios, a obispos, a las principales autoridades de las repúblicas italianas y al papa Gregorio XI. Tanta fama adquirió con sus misivas, que la enviaron a Aviñón como embajadora de la república florentina.

Aunque le pese a Groussac, la epístola de Isabel es obra de una mujer inteligente. Lo demuestra en cómo propicia la complicidad de su destinataria, mediante un discurso en el cual aparece un «nosotras» (las fatigadas, las luchadoras) frente a un «ellos» (los desmayados, los que muestran flaqueza). De hecho, salvo en el último párrafo, evita el «yo», y siempre habla de «las mugeres», o incluso de «ellas». Estamos ante una remitente culta, capaz de combinar un tono distendido y cómplice con los formalismos de las Cartas de Indias.

Cuando Alicia E. Poderti estudió la correspondencia escrita por mujeres desde el Tucumán colonial, observó tres formas de legitimar su discurso: «la evocación de nombres masculinos [...] la invocación de religiosos [...] y estrategias argumentativas» (2000, p. 176). Veamos cómo usa estos mecanismos Isabel de Guevara: ya hemos destacado que pone a los hombres de la expedición por testigos; además, en el párrafo final, alude a su marido, Pedro de Esquivel, también servidor de la Corona. No hay invocación de religiosos, pero sí una comparación de resonancias bíblicas (Ezequiel 26, 4:1-5:17): Isabel afirma «esta hambre fué tamaña, que ni de la Xerusalen se le puede ygualar». Por otra parte, toda la estructura del texto sigue el modelo de las ars epistolandi con sus partes organizadas en «saludo, exordio, narración, petición y conclusión», como destaca Marrero-Fente (1999, p. 100). Se trata, señala este autor, de una apelación «a una autoridad ausente (también femenina), a través de un acto de legitimación que se deriva de su conocimiento de los hechos» (ibid., p. 103).

Interés documental, belleza literaria, finura argumentativa y manejo del arte de la persuasión son elementos que Groussac no debió de percibir: por eso se burló de que quien escribió la carta anduviera «tan atrasado en noticias, que dirigía la epístola a la 'muy alta y muy poderosa princesa doña Juana' en julio de 1556: es decir, más de un año después de celebrarse sus exequias» (1916, p. 73). La respuesta cae por su peso: Isabel escribe $« \mathrm{~A}$ la muy alta y muy poderosa señora la Princesa doña Joana, Gouernadora de los reynos d'España, etc. en su Consejo de Yndias», como consta en el sobre de la misiva. Si esa «doña Juana» fuera Juana La Loca, llevaría, en efecto, un año muerta. Sin embargo, nadie que solicita un favor rebaja a una reina llamándola «princesa». Esto debería de haber hecho sospechar al historiador que no se refería a Juana I de Castilla, sino a Juana de Habsburgo, archiduquesa de Austria e infanta de España, que sí recibió el tratamiento de Princesa, y que actuó como Regente en ausencia de su hermano, entre 1554 y 1559. Es decir, que Isabel de Guevara, al contrario que el insigne historiador, sí sabía muy bien a quién se dirigía: a una princesa regente con fama de sagaz, enérgica y justa.

Continúa Groussac con sus argumentos descalificadores: «no se embarcaron con Mendoza tantas mujeres que pudiesen desempeñar el absurdo papel varonil que allí se describe» (1916, p. 74). Nos sorprende que el historiador tenga tal dato, ya que ni sobre la tripulación masculina hay acuerdo, pero Groussac sigue: «ni quizá viniera entonces la 'noble dama', sino en alguna de las expediciones inmediatamente posteriores» (ibíd.). Las comillas de «noble dama» nos remiten a su insistencia para darnos la imagen de que todas esas mujeres se dedicaban a la prostitución. Fantástico país España si sus rameras escribían como Isabel de Guevara...

Aun así, hay que reconocer que también pudieron viajar prostitutas en la armada mendocina. En la Instrucción iniciada en 1544 para dilucidar si Luis de Miranda había intentado asesinar a Irala y liberar a Cabeza de Vaca, piden a varios testigos: «declare que es lo que sabe cerca de las cosas y blasfemias que Luís de Miranda clérigo ha hecho». Juan García de Badajoz contestó lo siguiente:

estando en el puerto de Buenos Aires oyó [...] decir públicamente que Luís de Miranda había entrado en casa de una mujer enamorada [...] con una espada desenvainada y una capa revuelta al brazo echando cuchilladas diciendo pese a tal salga acá tu rufián
Mujeres en la expedición de Pedro de Mendoza: cartas, crónicas y novelas; verdades, mentiras, ficciones y silencios

MAR LANGA PIZARRO 


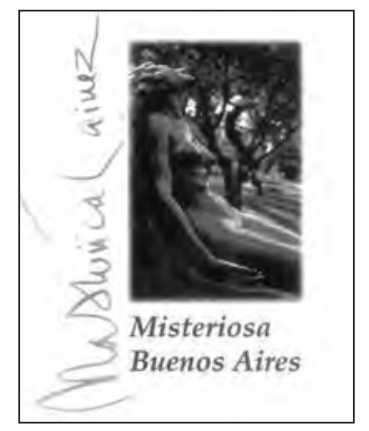

Manuel Mújica Láinez, Misteriosa Buenos Aires. Portada.

Mujeres en la expedición de Pedro de Mendoza: cartas, crónicas y novelas; verdades, mentiras, ficciones y silencios

MAR LANGA PIZARRO a matarse conmigo [...]. Que asimismo oyó decir [...] que Luís de Miranda y otros clérigos estando bailando de noche en una casa de ciertas mujeres enamoradas abrió la puerta con un manteo (Archivo General de Indias, Justicia, legajo 1131, folio 250).

Inmediatamente, también bajo juramento, corrobora los hechos Ruy Gómez Maldonado: «oyó decir públicamente que Luís de Miranda clérigo estando en Buenos Aires sobre una mujer enamorada hubo cierta cuestión con un mancebo que se llama Diego de Leyes» (ibíd.). Por el contexto (rufianes, bailes, peleas, cuchilladas), parece claro que estas «mujeres enamoradas» eran hetairas. ¿Significa esto que Groussac tenía razón al contradecir a Pedro de Lozano, negando la posibilidad de que las expedicionarias fueran esposas de los conquistadores? El historiador argentino consideró absurdo que los caballeros «trajeran a sus nobles consortes [...] para hacerles compartir los peligros y sufrimientos de la primera conquista» (Groussac, 1916, p. 73), y solo admitió «una que otra moza seguidora disfrazada de cobijera o ama de llaves; estas mismas no serían muchas; menos aun las esposas de buena ley» (ibíd.). Se equivocaba Groussac una vez más: de las seis mujeres que figuran adscritas a la expedición en la lista de pasajeros, únicamente Elvira Hernández no viajaba con su marido o su padre; de las veintidós que estudia Monte (2006), nueve iban con su familia; una, sola; y tres como criadas. Nada permite conocer con quién y con qué fines se embarcaron las demás.

Conviene volver a la especulación de Groussac, según la cual Isabel de Guevara podría no haber llegado a Asunción en 1536 sino posteriormente y, por tanto, estaría inventando su participación en los hechos que narra. De ser así, habría que reconocerle un excelente talento para lograr tal viveza con recuerdos fingidos. Groussac basa su idea en lo extraño que le resulta que Isabel deje pasar veinte años antes de escribir la carta. Villalta escribió su misiva aquí largamente citada el 22 de junio de 1556; justo siete días antes que Isabel. La carta de Villalta era ya conocida en 1615 por Antonio de Herrera, y Groussac la cita en múltiples ocasiones (1906, pp. 25, 64 y 65). Debiera de haberle bastado la «coincidencia» de fechas y pretensiones entre las dos cartas para alcanzar la solución al enigma: nombrado gobernador en 1555, «el 14 de mayo de 1556 Martínez de Irala promulga las Ordenanzas, por medio de las cuales se repartieron veinte mil indios» (Marrero-Fente, 1999, p. 107). Seguramente eso animó a Villalta y a Guevara a solicitar lo que no les habían otorgado, y les parecía lícito obtener. El momento propicio era aquel, no veinte años atrás, cuando Groussac hubiera deseado que Isabel escribiera.

Consideramos que queda claro que, a pesar de la objeciones de Groussac, Isabel de Guevara escribió su hermosa carta. Pero ¿quién era esa mujer? No figura en la incompleta lista de expedicionarios, donde sí aparece el siguiente apunte: «domingo de guevara e don vitor de guevara, hijos de don carlos de guevara e doña ysabel de laserna, natural de toledo, pasaron en la dicha armada» (Peña, 1936, p. 27). ¿Quiénes pasaron: solo los hijos, o también Isabel y Carlos? El último sí lo hizo, según consta en varios documentos oficiales: Carlos I lo nombró factor y oficial real; fue capitán de la nave Santa Catalina; el 15 de junio 1536, venció a los indios querandíes en Corpus Christi, batalla en la que también participó Schmidl; y murió, junto a Ayolas, en un combate contra los guaicurús. Gladys Lopreto (1987, p. 46) apunta la posibilidad de que Isabel de Laserna, la esposa de Carlos de Guevara, sea Isabel de Guevara. Sin embargo, nos parece extraño que Isabel adopte en 1556 el apellido de su primer marido, ya muerto, puesto que no lo hace con el del segundo, que está vivo. Además, si realmente Isabel de Guevara hubiera estado casada con un conquistador que había perecido víctima de los indígenas, imaginamos que lo hubiera mencionado, como un mérito por el que ser recompensada.

Otro hilo para averiguar la identidad de Isabel es Pedro de Esquivel. Un sevillano con tal nombre figura en la lista de tripulantes que viajaron con Cabeza de Vaca. El 27 de agosto de 1564, Pedro de Esquivel testificó en el informe de Pedro Fernández (BGI, Doc. VIII, 61-97). Díaz de Guzmán lo sitúa batallando contra los indígenas en 1560 (p. 114); y, en 1571, maliciando una conjura, «mandó él [Felipe de Cáceres] prender algunas personas de sospecha, y entre ellas un caballero llamado Pedro de Esquivel, natural de Sevilla a quien mandó dar garrote, y cortar la cabeza, y ponerla en la picota» (p. 134). Lo mismo relata Centenera: «en su prisión afirma, y en la plaza / le corta la cabeza, y en picota / la fija, y de traidor le reta y nota» (vv. 2262-2265). También un Esquivel, sin nombre propio, recibe 
el solar 89 en el reparto de tierras de Buenos Aires, en 1580.

El tema se complica cuando Lafuente Machaín (1943, p. 210) afirma que existieron dos Pedro Esquivel, ambos sevillanos, y ambos llegados a Asunción con Cabeza de Vaca. Uno habría estado casado con Isabel, y sería padre de Gabriel de Esquivel y Cabrera. Del otro, se conserva un testamento (1547), en el que se declaraba casado con Ana de Guevara. Según recoge Monte, Esquivel confesó en este documento: «durante el tiempo de su matrimonio siempre ha gastado de la hacienda de su esposa, a quien rogaba le perdonase». Además, Monte apunta la existencia, en los arhivos de Asunción, del borrador de testamento de doña Ana de Guevara (1559), vecina de Asunción, y «casada legítimamente con Pedro de Esquivel, su heredero y albacea» (p. 544). Con esos datos, Monte señala la posibilidad de que Isabel de Guevara y Ana de Guevara sean la misma mujer, cuyo nombre real podría ser Ana Isabel.

Fuera quien fuese Isabel de Guevara, su carta constituye un precioso documento para acercarnos a la expedición de Mendoza desde una novedosa perspectiva: gracias a ella, las mujeres dejan de ser silenciadas para convertirse en heroínas, en auténticas salvadoras.

\section{Las mujeres de la expedición mendocina en la literatura}

La expedición mendocina tiene todos los ingredientes necesarios para convertirse en materia literaria: un viaje azaroso por el océano; un asesinato; el asentamiento en tierras extrañas, con ataques indígenas y hambruna que lleva al canibalismo; la figura casi mítica de La Maldonada; la fundación de Asunción; las incursiones en territorios remotos y peligrosos; la presencia de mujeres de todas las clases sociales; la rencillas entre españoles y sus luchas por poder... Sin embargo, no conocemos demasiadas obras que hayan utilizado este tema.

El grupo «Los títeres de Horacio» basó en Díaz de Guzmán su texto de creación colectiva La Maldonada, representado en Madrid (1981) y posteriormente en varias ciudades españolas. En 2006, fruto de la colaboración de tres autoras bonaerenses (Estela Martínez Luna, Ana María Zetina y Luisa de la María), apareció la novela Aguas de Puma, protagonizada por La Maldonada. Su trama coincide con la ya conocida hasta que Maldonada ayuda a parir a una hembra de jaguar. Los indígenas consideran este hecho como mágico, y la acogen en sus tolderías. A partir de ese momento, la novela se centra en la descripción de las costumbres guaraníes: Maldonada adopta la ropa, los tatuajes, los usos nativos; y se une a Bagual bajo el ceibal sagrado donde los españoles habían violado y quemado viva a la princesa Anahí. Dirigida a un público adolescente, Aguas de Puma tiene una obvia finalidad didáctica, pero no deja de ser una obra sobre buenos y malos: los españoles son crueles; los indígenas dialogantes (casi democráticos), hábiles argumentadores, y respetuosos con la naturaleza.

A Isabel de Guevara le dedicó uno de sus Romances de la conquista Hugo Rodríguez Alcalá (2000, pp. 27-30). Y volvemos a encontrarla en el monólogo teatral sobre su figura (escrito por Alicia Muñiz y dirigido por María Esther Fernández) que se representaba en Buenos Aires, en 2004. Por su parte, el ciclo «Noches de Luna y Misterio» organizado por el Gobierno de Buenos Aires en 2008, convirtió a Ana de Arrieta en uno de los personajes gestados por Eduardo Gudiño Kieffer y narrados por Rosalinda Varveri: un fantasma que contaba la historia de la cabeza de pescado, y vagaba desde Riachuelo hasta la Plaza San Martín.

Aunque no estén específicamente dedicadas a las mujeres de la expedición, otras obras les dan cabida en sus páginas.

Mujica Lainez, en el cuento «El primer poeta 1538», presenta a Ana de Arrieta «en el portal de su casa, muy perseguida por tres de los extranjeros melosos, quienes le ofrecían en venta mil tentaciones [...] como si en lugar de una aldeana sencilla hubiera sido una rica señora de Venecia» (1985 [1951], p. 13). Para construir el personaje de Isabel de Guevara, utiliza la carta, cuya valía reconoce. Ni eso evita que la acabe condenando a la prostitución:

Es la mejor. En tiempos del hambre y del asedio, dos años atrás, se portó como ninguna: lavaba la ropa, curaba a los hombres, rondaba los fuegos, armaba las ballestas. Una maravilla. Ahora es una enamorada más, y en ese arte, también la más cumplida (ibid., p. 12).

Al recrear el enfrentamiento entre Luis de Miranda y Diego de Leys, el narrador pone

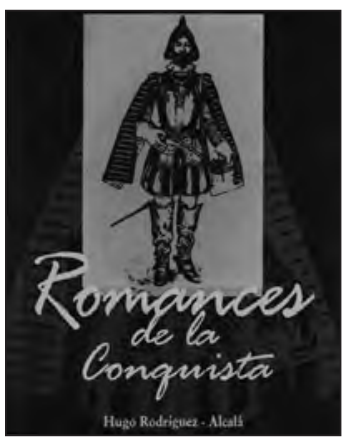

Hugo Rodríguez Alcalá, Romances de la Conquista. Portada. 


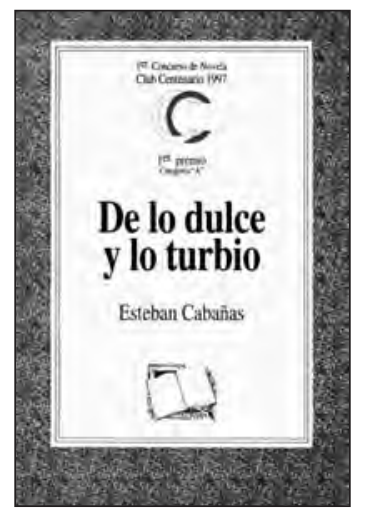

Esteban Cabañas, De lo dulce y lo turbio. Portada.
Mujeres en la expedición de Pedro de Mendoza: cartas, crónicas y novelas; verdades, mentiras, ficciones y silencios

MAR LANGA PIZARRO rostro a esa «enamorada» cuyo nombre nos escamoteron los testigos judiciales de 1544. Lo que no hicieron sus contemporáneos, lo hacen los literatos, e Isabel de Guevara deviene el motivo de la disputa. Cuando el poeta va a casa de Isabel para leerle sus versos, la encuentra en medio de una bulliciosa orgía:

logra Luis de Miranda llegarse hasta el lecho. [...] Diego de Leys, el bravucón, borracho como una cuba, $[. .$.$] le arroja a la faz un chorro de perfume.$ [...] Ciego, el poeta saca el espadón [...]. Su vino tampoco le permite conservar el equilibrio [...]. Diego de Leys salta sobre él, aprovechando su ceguera, y le corta el pómulo con el cuchillo. Lanza Isabel un grito agudo. [...] Desnuda, hermosísima, se desliza entre los genoveses que se han abalanzado sobre su pobre amigo. [...] Pero es inútil. Entre cuatro alzan en vilo al intruso, abren la puerta y le despiden como un bulto flaco. El resto, enardecido por el roce de la enamorada, la ha derribado en los revueltos cojines y se ha echado sobre ella, en una jadeante confusión de dagas, de botas y de juramentos. Luis de Miranda recoge el manuscrito [...]. Llora en silencio (ibíd., pp. 15-16).

En la primera de las novelas que componen la trilogía dedicada a su ciudad natal, Primer cielo de Buenos Aires (1960), Leónidas Barletta cede un lugar de relieve a María Dávila: ella es quien elige a Catalina Pérez para que entre al servicio del adelantado (p. 121), quien le advierte que puede acabar cometiendo una injusticia con Osorio (p. 165), quien consuela a Elvira Pineda (p. 168). Además, aparecen otras mujeres: "convidó a almorzar don Pedro a la mujer de Osoro, Elvira Pineda [...]; a Isabel de Guevara, [...] a la Maldonada y junto a él sonreía María Dávila con sus grandes ojos rasgados» (p. 95).

Los caballos de don Pedro de Mendoza (1968), de Josefina Cruz, ofrece una imagen bastante tópica de las expedicionarias: aunque asisten a los soldados malheridos («Doña Isabel y Catalina Pérez corren a socorrerlos», p. 77), y califica a María Dávila de «fiel compañera del adelantado» (p. 35), considera que estas mujeres eran prostitutas: salvo «doña María de Angulo e Isabel de Guevara [...] el resto son hembras que quemaron sus naves entre la chulapería de Sevilla y los puertos de Cádiz y de San Lúcar» (p. 34); «la más admirada y desada por todos es la joven Elvira Pineda. La Elvira es una fresca, una barragana... pero es tan hermosa y engañadora $i \mathrm{Si}$ hasta el propio adelantado se ablandó con sus ruegos!» (ibid.).

Las piedras del Guairá (1996 [1993]), del madrileño Rubén Caba, es una novela histórica tradicional, cuya acción transcurre durante los cinco primeros años de asentamiento español en el Río de la Plata. Como hiciera Mujica Lainez, cuando Caba reconstruye el encontronazo entre Diego de Leyes y Luis de Miranda (p. 32), lo explica porque el primero ofendió a «Isabelita la fogosa (a la que las adversidades convertirían en la heroína Isabel de Guevara)» (p. 78). Debido a los problemas que generaban, «Ruiz Galán había decidido podar los excesos putañeros a que se entregaban los soldados» (p. 177). Aparece Elvira Pineda, que vaga como «alma en pena. Vestida de luto» (p. 78), mientras María Dávila y Ana de Arrieta llevan «camisas bordadas, pañuelitos de encaje y cofias con chatones de oro» (p. 78), y Mari Sánchez, «la mujer de Juan Salmerón» (p. 28), se convierte en cantinera. Junto a ellas, hay mujeres inventadas, como Lorenza la Casta y Petra Burgillo.

El escritor argentino Ángel Balzarino recrea, en el relato «La Sentencia» (1995), el momento de la ejecución de Osorio: mediante un juego en que se hacen simultáneos los pensamientos de los tres protagonistas, observamos cómo convencen a Pedro de Mendoza para que dicte sentencia. Podríamos esperar que Osorio acudiera al encuentro de Elvira, pero se reúne secretamente con Catalina Pérez, con la esperanza de llegar a puerto para vivir con ella. Y Catalina, que comparte ese sueño, es testigo de cómo apresan a su amante para ejecutar la sentencia.

El paraguayo Carlos Colombino, que firma De lo dulce y lo turbio (1997) como Esteban Cabañas, juega con las voces narrativas, la intertextualidad y la ironía para componer una novela centrada en Irala, desde el momento del asesinato de Osorio hasta la muerte de Ayolas. Al contrario de lo que realmente sucedió, Elvira Pinedo abandona la expedición: «al lado del cuerpo ondea un ropaje de tela aplastada sobre el pecho. Es Elvira a quien nadie ha podido apartar de Osorio» (p. 14). También aparece María Dávila, personaje secundario que «sufre de igual dolencia que don Pedro» (p. 28) y «vive curándole las llagas» (p. 52), hasta que el cadáver del adelantado es arrojado al océano, y ella queda «alejada cual una sombra, en el fondo» (p. 83). Uno de los rasgos posmodernos del relato son las 
anacronías: Rodrigo de Cepeda recita algunos versos que escribiría Teresa de Jesús años más tarde; y la historia de La Maldonada sufre una irreverente transformación:

había decidido volverse hombre. [...] «Desde hoy, me llamo Fernán» [...] ya era fea de mujer; de hombre resultó un horror. Por eso, cuando pretendió seducir a la Maldonada, ésta [...] pensó con furia: «Ya es bastante con sufrir el encierro, la escasez, la falta de comestibles o, en su defecto, comerse a los ajusticiados, a sapos y lagartijas, para tener que soportar el asedio de Fernán». Y decidió fugarse. [...] Una puma trataba de parir [...]. La ayudó en ese menester [...]. Allí estuvo la Maldonada un mes entero. La puma le traía algo de comer cuando venía a amamantar a sus hijos, pero los indios del lugar, descubriendo su escondite, la tomaron prisionera y la devolvieron al fuerte (pp. 67-68).

El anacronismo también llega inserto en una falsa cita de Nicolás del Techo: «a fin de que los hombres no pareciesen más crueles que los tigres, fue absuelta. [...] ¡Vaya la varia suerte! Sobre todo si tuvo que sufrir el asedio del Fernán por el resto de su vida» (p. 69). Tampoco duda Colombino en inventar una descripción para Isabel de Guevara «tenía veintitrés años. Parecía menor: era de piel blanquísima, pelo negro y ojos oscuros» (p. 51 ), ni en hacerla protagonizar una escena de canibalismo, de esas que la auténtica Isabel silenció en su carta.

El también paraguayo Luis Hernáez, a través de un estilo ágil y de continuos saltos temporales, presentó en Este interior reino de nada (2003) la atrayente personalidad de Irala, sus exploraciones por el Chaco, las relaciones con los (sobre todo, las) indígenas, la distribución de las primeras encomiendas, la revolución de los Comuneros, los continuos enfrentamientos entre los españoles. "Te regodeas creando una realidad a la medida de tus intereses, creando un reino interior que no es tal», lo acusa Pedro de la Torre (p. 190). Algunas de las expedicionarias se evocan desde el recuerdo: Isabel de Guevara surge asociada a la hambruna (p. 27); Elvira aparece, como en su declaración judicial, gritando desesperada, hasta que la amenazan de muerte también a ella (pp. 48-53). Las demás, las que ocupan el presente temporal de la narración, son auténticas señoras. El narrador se pregunta qué le pudo pasar al padre de Carmen para que «viera con buenos ojos que ella y otras res- petables aunque necesitadas damas vinieran con [...] don Pedro» (p. 67). Posteriormente, Carmen se resigna a su destino de vivir con un hombre al que no ama, de compartirlo con las indígenas, de ser apartada de su lado cuando él se subordina a la decisión de Irala de casarlo con una de sus hijas mestizas.

Recientemente, se ha publicado el cómic Jusepe en Amérique (2009), con dibujos de Pablo Túnica y texto de Carlos Trillo. El primero de ellos declaró en 2008 que consideraba la expedición mendocina «una historia muy divertida para dibujar, llena de necrofagia y cosas tétricas». El protagonista de la historieta es Jusepe, un enano conspirador, encargado de vaciar el orinal de Don Pedro. Desde su perspectiva, asistimos a los ataques aborígenes, la hambruna, el canibalismo, las disputas entre los conquistadores, $\mathrm{y}$ las apariciones del fantasma de Osorio. Aparecen solo dos mujeres: Elvira, que se ha embarcado disfrazada de hombre; y María Dávila, que conspira con Ayolas para desbancar a Mendoza. Hermosa y joven la una, de nariz aguileña la otra, los trazos del dibujante sustituyen a menudo las palabras, porque puebla los rostros de gestualidad.

Con tan poca información como tenemos sobre las mujeres que acompañaron a Mendoza, no resulta difícil crearles semblantes, inventarles pasados, futuros y hasta presentes. De ese modo, la literatura las rescata del silencio al que las sometieron sus compañeros de expedición. Sin embargo, en ocasiones, también las catapulta para siempre desde prejuicios milenarios.

\section{Bibliografía}

Anales de la Biblioteca (1912), Vol. 8, Buenos Aires, Coni Hermanos.

Balzarino, Ángel (1995), «La Sentencia», Hombres y hazañas. Digitalizado en http://www.bibliotecasvirtuales.com/biblioteca/narrativa/AngelBalzarino/Hombresyhazanas/index.asp

Barletta, Leónidas (1960), Primer cielo de Buenos Aires, Buenos Aires, Goyanarte.

Berg, María Graciela (2006), «Sitiada, oprimida, angustiada... Quejas al rey de España de doña Claudia García de Arcos, Buenos Aires 1714-1716», en Márgara Russotto, La ansiedad autorial: formación de la autoría femenina en América Latina: los textos autobiográficos, Caracas, Equinoccio, pp. 98-110.

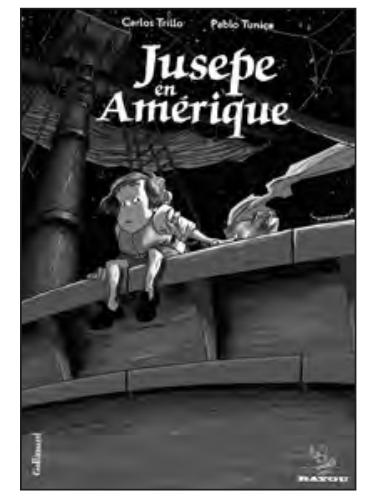

Carlos Trillo y Pablo Túnica, Jusepe en Amérique. Portada.

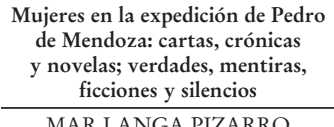

MAR LANGA PIZARRO 
Caba, Rubén (1996), Las piedras del Guairá, Madrid, Fondo de Cultura Económica.

Centenera, Martín del Barco (1854 [1602]), La argentina o La conquista del Río de la Plata: poema histórico, Buenos Aires, Imprenta de la Revista.

Colombino, Carlos (1997), De lo dulce y lo turbio, Asunción, Club Centenario.

Condés Palacios, María Teresa (2002), Capacidad jurídica de la mujer en el derecho indiano (Tesis doctoral), Universidad Complutense de Madrid. Digitalizada en http://www.ucm.es/BUCM/tesis/ghi/ ucm-t26712.pdf

Cruz, Josefina (1968), Los caballos de don Pedro de Mendoza, Buenos Aires, Goncourt.

Da Luz, Patricia (2001), «Mujeres del olvido, heroínas de la historia», La Revista. Diario Primera Edición, 22 de julio.

Díaz de Guzmán, Ruy (1835 [1612]), Historia argentina del descubrimiento, población y conquista de las provincias del Río de la Plata, Buenos Aires, Imprenta del Estado, Tomo I.

Fitte, Ernesto J. (1980), Hambre y desnudeces en la Conquista del Río de la Plata, Buenos Aires, Academia Nacional de la Historia.

Fuentes y Guzmán, Francisco Antonio de (1882), Recordación florida. Historia de Guatemala, Madrid, L. Navarro.

Gandía, Enrique de (1943), «Lucía Miranda y La Maldonada» en Introducción a Ruy Díaz de Guzmán, La Argentina, Buenos Aires, Ángel Estrada y Cia. Editores.

Gandía, Enrique de (1986), edición de la obra de Ruy Díaz de Guzmán, Historia argentina del descubrimiento, población y conquista de las provincias del Río de la Plata, Madrid, Historia 16.

Garcilaso de la Vega, Inca (1829 [1609]), Comentarios reales, 2, Madrid, Imp. de los Hijos de Catalina Piñuela.

Gil, Juan (1985), «El rol del tercer viaje colombino", Historiografía y Bibliografía Americanistas, $\mathrm{n}^{\circ}$ 30, pp. 83-110.

Groussac, Paul (1916), Mendoza y Garay: las dos fundaciones de Buenos Aires, 15361580, Buenos Aires, J. Menéndez.

Guevara, Isabel de (1877 [1556]), «Carta de doña Isabel de Guevara», en Cartas de Indias, Madrid, Ministerio de Fomento, pp. 619-621. Digitalizada en http:// www.cervantesvirtual.com/FichaObra. html?Ref=4911
Hernáez, Luis (2003), Ese interior reino de la nada, Asunción, Servilibro.

Herrera y Tordesillas, Antonio de (1615), Historia general de los hechos de los castellanos en las Islas y Tierra Firme del mar Océano que llaman Indias Occidentales (Décadas 5 y 6), Madrid, Juan de la Cueva.

Iglesia, Cristina (2006), «La mujer cautiva: cuerpo, mito y frontera», en Georges Duby y Michelle Perrot (dirs.), Historia de las mujeres (tomo 3). Del Renacimiento a la Edad Moderna, Madrid, Taurus, pp. 583-597.

Jesús, Teresa de (1861 [1560]), La vida de la Santa Madre Teresa de Jesús, y algunas de las mercedes que Dios le hizo, escritas por ella misma, Madrid, M. Ribaneneyra.

Lafuente Machaín, Ricardo de (1943), Conquistadores del Río de la Plata, Buenos Aires, Ayacucho.

León Guerrero, María Montserrat (2000), El segundo viaje colombino (Tesis doctoral), Universidad de Valladolid. Digitalizada en http://www.cervantesvirtual.com/FichaObra.html?Ref $=7779$

López, Vicente Fidel (ed.) (1975), Historia de la República Argentina: su origen, su revolución, su evolución y su desarrollo politico, vol. 7, Buenos Aires, Sopena.

Lopreto, Gladis (1987), La carta de Isabel de Guevara, Asunción, Instituto Histórico de la Municipalidad.

Madero, Eduardo (1955 [1892]), Historia del puerto de Buenos Aires, Buenos Aires, Compañía Imprenta Argentina.

Marrero-Fente, Raúl (1999), Al margen de la tradición: relaciones entre la literatura colonial y peninsular en los siglos $X V, X V I$ y XVII, Madrid, Fundamentos.

Martínez Luna, Estela; Zetina, Ana María; María, Luisa de la (2006), Aguas de Puma, Buenos Aires, Corregidor.

Medina, José Toribio (1889), Colección de documentos inéditos para la bistoria de Chile desde el viaje de Magallanes hasta la batalla de Maipo, 1518-1818, vols. 3-4, Santiago de Chile, Imprenta Ercilla.

Medina, José Toribio (1908), El veneciano Sebastián Caboto a1 servicio de España y especialmente de su proyectado viaje a las Molucas por el Estrecho de Magallanes, Santiago de Chile, Imprenta Universitaria, vol. 1. 
Miranda, Luis de (1947 [1545?]), «Romance indiano», en Carlos R. Centurión, Historia de las letras paraguayas, Buenos Aires, Ayacucho.

Monte, María Graciela (2006), «Las mujeres del siglo de Irala», Anuario de la Academia Paraguaya de la Historia, vol. XLVI, Asunción.

Mujica Láinez, Manuel (1985 [1951]), Misteriosa Buenos Aires, Barcelona, Seix Barral.

Peña, Enrique (1936), Documentos relativos a la expedición de don Pedro de Mendoza y acontecimientos ocurridos en Buenos Aires desde 1536 a 1541, Buenos Aires, Imprenta Ángel Curtolo.

Piossek Prebischa, Teresa (2003), «Las conquistadoras. Presencia de la mujer española en América durante el siglo XVI», Revista de la Fundación Cultural de Santiago del Estero, $\mathrm{n}^{\circ} 17$.

Poderti, Alicia E. (2000), «Hacia la descolonización del discurso femenino: textos 'escritos' por mujeres en el Tucumán colonial (siglos XVII y XVIII)», Cuadernos de la Facultad de Humanidades y Ciencias Sociales (Jujui).
Rodríguez Alcalá, Hugo (2000), «Isabel de Guevara escribe su famosa carta. Junio, 1556", Romances de la conquista, Asunción, (Ingrapar), pp. 27-30.

Rossi de Fiori, Iride (et al., ed.) (1997), Primera escritura femenina en la República Argentina: poemas del Carmelo de Córdoba (1804), Salta, EUCASA / B.T.U.

Schiess, Amy (2006), «Manipulaciones de la carta: tres escritoras hispanoamericanas» en Márgara Russotto, La ansiedad autorial: formación de la autoría femenina en América Latina: los textos autobiográficos, Caracas, Equinoccio, pp. 111-126.

Schmidl, Urich (1903 [1567]), Viaje al Río de la Plata, Buenos Aires, Cabaut y Cía.

Schultz, Fryda (2006 [1936]), Tres poetas de la fundación, Buenos Aires, Baires Popular.

Torre Revello, José (1941), Documentos históricos y geográficos relativos a la conquista y colonización rioplatense: Litigios motivados por la expedición de Don Pedro de Mendoza, Buenos Aires, Editor Talleres S.A.

Trillo, Carlos y Túnica, Pablo (2009), Jusepe en Amérique, París, Gallimard.
Mujeres en la expedición de Pedro de Mendoza: cartas, crónicas y novelas; verdades, mentiras, ficciones y silencios

MAR LANGA PIZARRO 